\title{
Raising environmental awareness as a meaningful factor of integrated waste management in Moscow
}

\author{
Nadezhda Abramova ${ }^{1, *}$ \\ ${ }^{1}$ Moscow State University of Civil Engineering, 129337, 26 Yaroslavskoye sh., Moscow, Russia
}

\begin{abstract}
Abstact. The article is aimed at evaluating the prospects of promoting environmental awareness among the population in Moscow. To meet the goal, the author analyzed foreign studies on environmental awarenessbuilding. The following methods were used during the research: the investigation of the legal and regulatory framework, analysis of surveys performed by the Public Opinion Foundation (FOM) and Levada Analytical Center, content analysis of the Moscow media sources with the use of the Public.ru database, and exploration of TV programs on Moscow 24 channel. The research indicated the key problem that is a low engagement of the population into the practice of separate waste collection. It undermines the process of integrated waste management in Moscow. The author uses a public-opinion survey to identify the reasons for such low engagement of the population. Those reasons include the lack of time for sorting, the lack of space in an apartment for arranging waste sorting, the lack of trust in a newly established infrastructure. The conclusion is that it is necessary to not only conduct awareness-raising campaigns but to educate the population as well. It is reasonable to arrange lessons on environmental protection to foster environmental awareness in children. When conducting awareness-raising campaigns, it is important to focus on increasing public confidence in the established infrastructure. For example, it makes sense to share information about transporting garbage from containers to sorting stations, and demonstrate how the sorting stations operate.
\end{abstract}

\section{Introduction}

To implement the Federal Law N 89-FZ14 on Production and Consumption Wastes promulgated on June 24, 1998, the government has introduced some changes in waste management in Moscow. A program on a separate collection of waste has been launched. According to the statistics of the city administration, $20 \%$ of municipal solid waste was recycled in 2019 [3], and this indicator should grow up to $60 \%$ by 2024 . It is important to reduce the number of waste landfills from both environmental and social points of view. A well-coordinated process of separate collection of waste is possible in case of a responsible approach of the city administration and the citizens. The city administration started to

* Corresponding author: AbramovaNV@mgsu.ru 
expand the waste management structure, they are namely paying more attention to separate collection of waste and recycling. They conduct work to raise the environmental awareness of the population regarding the separate collection of waste as one of the key factors of waste management.

It is necessary to rely on not only awareness-raising campaigns but on educating the population as well. The Federal Law No. 7-FZ on Environmental Protection states that "ecological enlightenment shall be pursued for the purposes of shaping up an ecological culture in the society, fostering a careful attitude to nature, rational use of natural resources by means of disseminating ecological knowledge on ecological safety, information on the condition of the environment and on the use of natural resources". The development of the ecological culture among the population will eventually lead to the introduction of practices for sorting waste. Ecological enlightenment may influence the citizens' attitude and perception so they sympathetically consider waste sorting. It is important to eliminate the citizens' blockers and hesitations while forming this new attitude. Moreover, education allows forming of new values-based orientations, and it requires a long time. The awareness-raising programs among pupils and students bring the greatest results.

Overall, this program is no so new for Russia. There was an infrastructure for separate collection of waste in the Soviet Union, namely recycling centers for glass containers and waste paper. The main motivation was a monetary reward for bringing used glass containers and coupons for purchasing goods in short supply. By the middle of the 1990s, the existing soviet system for separate collection of waste was destroyed. There were some attempts in 2014-2015s in Moscow. At that time, the centers for separate collection of waste and for collection of glass containers in Moscow. Now more project was launched in November 2018. Moscow introduced Bell-type containers for the selected collection of waste, serviced by "Ecotechprom" state unitary enterprise. Starting from 2019, "Ecoline" and other similar companies have been installing containers for recyclable items in the courtyards of residential blocks.

A number of pilot projects introducing the system of separate collection of consumption waste have been implemented in Moscow since 2014, however, the citizens have not demonstrated a significant improvement in this direction yet. The author has analyzed the experience and best practices of theorists and specialists in the field of environmental awareness-building and the implementation of separate waste collection approaches.

\section{Literature review}

British researchers consider that the specific information regarding the structure of waste management, what applies to recyclables, the location of containers for recyclable items, and the way of its disposal can encourage the better involvement of population into the waste sorting process [1]. Besides, such aspects as the information regarding waste management logistics [2], and the installation of containers for waste sorting and their availability [3] increase the involvement of the population, while the appearance and size of trash bins are one of the barriers to recycling community waste [4].

Environmental awareness means "the ability of individuals to identify a number of characteristics, concepts and behavioural patterns associated with environmental protection" [5]. Numerous studies have proved that environmental awareness is an important factor of individual's perception and behavior in the environment [6]. some researchers believe that people can raise their environmental awareness by different means. Not only knowledge, but also environmental values can influence the formation of environmental behavior [7]. Previous studies have also demonstrated that case-based environmental information from local communities can influence the consumer behavior more than widely promoted information [8]. Therefore, it is necessary to combine 
environmental awareness and propaganda for environmental protection on the governmental level.

It is also important to get feedback from population in the process of creating waste management system. Such connection with citizens allows city administration to assess the performance of contractor companies, evaluate the level of satisfaction and trust of population, and understand the gaps in the management system. For example, 5 cities in Morocco launched a Citizen Report Card program reaching 25\% of Morocco's urban population. The city administration uses the results of the survey to assess the quality of service provided by private contractors, and to make decisions on prolongation of agreements with them. In Maputo city (Mozambique) there is a digital platform that allows citizens to report concerns [9]. These forms of citizens' involvement allow establishing connections between governmental authorities and population.

And in the process of analyses, a number of obstacles in this strategy have been indicated. So, according to the results of studies in foreign countries, infrastructural factors play an important role [10-11] and the amount of effort to sort waste in households [12-14]. One more key factor is the level of education among population [15-17, 19-20]. Russian sociologists discovered the fragmentation of the modern practices targeted at mitigating the problem of waste in Russia [21].

\section{Research methodology and sources of information}

The analytical review is a desk study using the example of Moscow. The review presents the investigation of legal and regulatory documents, primarily the territorial waste management scheme in Moscow, in order to indicate the changes introduced in separate collection of waste in 2020 . And then the author analyzes the weekly survey performed by the Public Opinion Foundation (FOM) on February 22-23, 2020, and the survey performed by Levada Analytical Center on March 21-27, 2019. Those surveys allowed to understand what opinion on garbage removal and sorting the public had. 1500 respondents took part in the survey by the FOM, and 1600 people took part in the survey by Levada Analytical Center. To analyze the awareness of the population, the author explored TV programs for 2020devoted to separate collection of waste on Moscow 24 channel, and performed the content analysis of the Moscow media sources with the use of Public.ru database. Public.Ru funds contain publications of over 10,000 media sources such as newspapers, magazines, news agencies, TV channels, radio stations, and Internet publications. The analysis focused on mass media in Moscow.

\section{Results}

8.0 million tons of municipal solid waste are generated annually in Moscow. In 2020, the territorial scheme of Moscow introduced a new definition - separate accumulation of waste (RNO) - separate storage by type of waste, waste groups, groups of homogeneous waste [22].

Separate collection sites for municipal solid waste were established in the city and Public information on the implementation of separate collection has been initiated. A twocontainer waste collection system is being implemented in the capital. Trash bins of two colours are installed in the city: blue - for recycled materials (glass, plastic, metal, paper) and gray container for mixed domestic waste (other waste) [23]. New requirements to waste containers sites were also introduced. The site should have information on the service companies responsible for the contents waste collection sites and organizations. As well as on the site should be placed the marking elements, where the blue and gray container is 
installed. But nothing is said about re-equipment of already existing sites. Also, there are no instructions for propaganda information, which is placed on the garbage sites. And nothing is said about leaflets in the entrances of houses, so that residents get information about new containers and sorting methods. There is also no information about the conditions for organizing sorting in houses with garbage chutes. Garbage removal machines are also indicated in blue and grey. Wasteremoval trucks are sent to specially equipped companies, where the sorting of waste is carried out. To inform the population, a single call center operates at the State Unitary Enterprise "Ecotechnprom". Information boards with information about transport and management companies were installed near the waste collection sites.

At the same time, garbage from other waste containers continues to be disposed of most of the waste is recycled in the Moscow region, but the capital's waste is also sent to other regions - Kaluga and Vladimir regions.

For the system of separate garbage collection to work, it is necessary to conduct a broad public awareness campaign. It is necessary to inform which waste is treated as recycled and where the waste is exported. When analyzing the regulatory documents, we did not find information in which media the explanatory campaign will be conducted and how propaganda information will be placed on waste storage sites and in the entrances of houses. This made our subsequent analysis somewhat difficult. We have analyzed regional press and channels "Moscow 24".And it may be recommended to add more detailed information about the information campaign, as well as its goals and objectives. Besides, normative documents do not contain information about feedback of city authorities with population on waste sorting issues, which reduces confidence of population to new waste management system.

\subsection{Public awareness of waste collection}

A separate collection system was launched in January 2020.At the end of February, FOM conducted a public awareness study on the issue [24].

For the general population, the most pressing problem is that of unsorted waste in a bins. One of the answers of respondents is "No separate collection. There are names of bins, but people still dump everything in one pile, there are not enough bins, and bags of waste are piled near the bins" [24].

The results of the survey showed that Muscovites positively assess the situation on the organization of household waste collection in Moscow.72\% of Moscow are convinced that household waste removal is well organized, which is $24 \%$ higher than in general Fig. 1. 


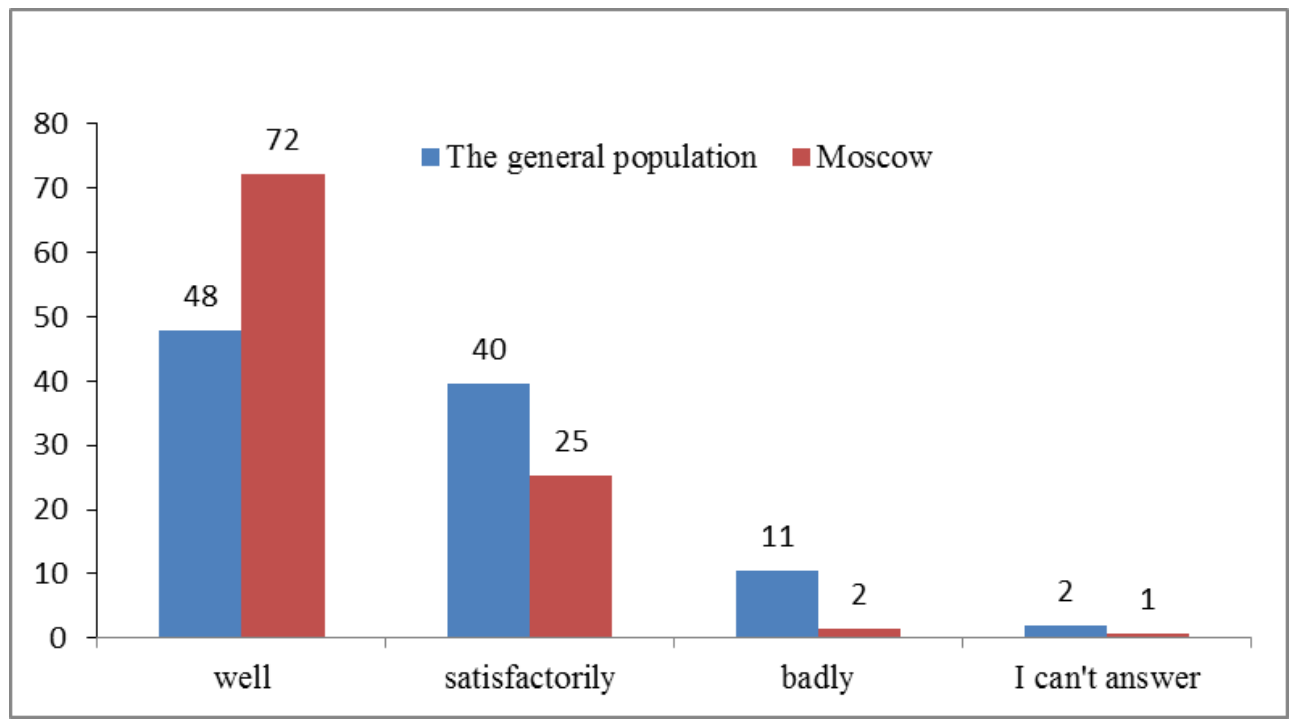

Fig. 1.Generally speaking, is the disposal of household waste organized well, satisfactorily, or poorly where you live? (FOM, 2020) [24].

However, $48 \%$ of Muscovites found it difficult to answer with regard to household waste disposal, which indicates a lack of information on this issue Fig. 2. Therefore, it is necessary to organize an information campaign to educate the population on this issue [24].

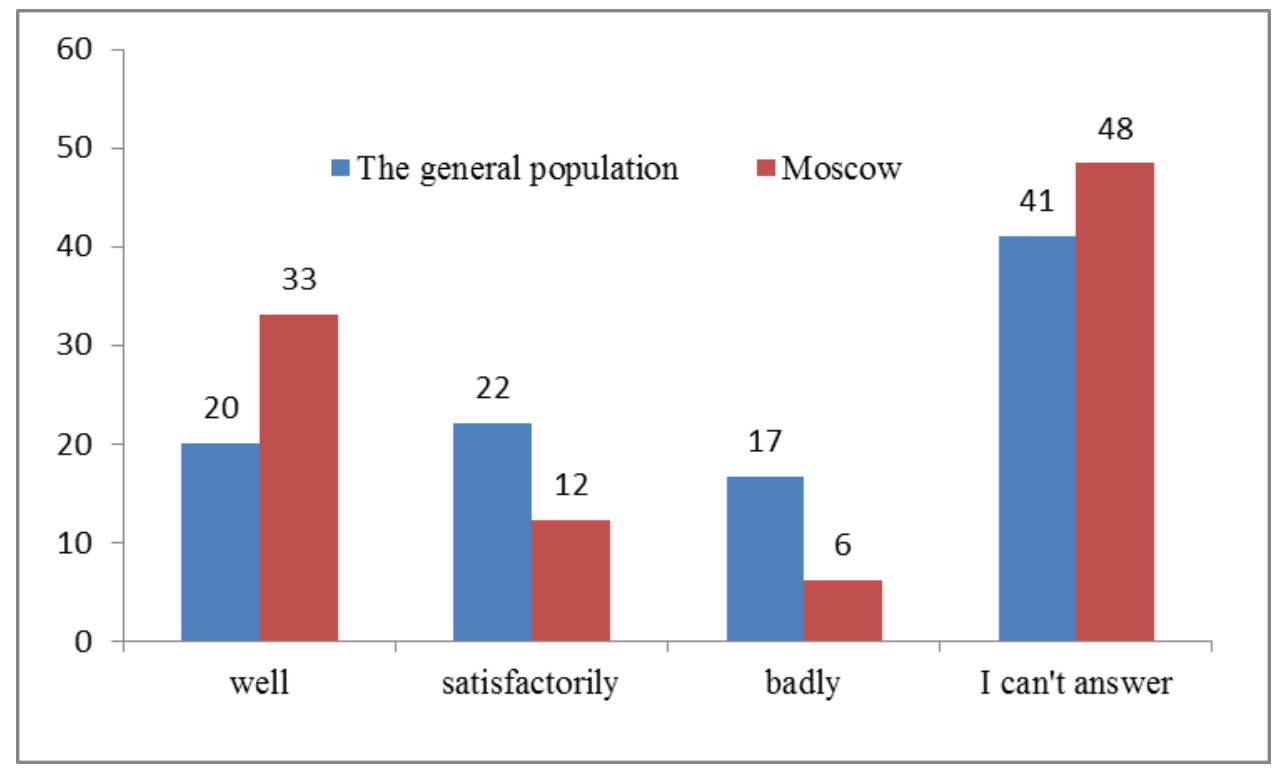

Fig. 2. Is the disposal of household waste, that is, the work of landfills and landfills where you live, organized in general well, satisfactorily or poorly? (FOM, 2020) [24].

According to a survey of 2019 in Moscow, 18\% of respondents have already sorted waste at home, and $37 \%$ expressed willingness to join this practice Fig. 3. Respondents who were not ready to sort the waste were asked about the reasons. $36 \%$ of them replied that they did not have time, 30\% explained that there was no place at home, $27 \%$ are mistrustful of further processing, $18 \%$ believe that waste should be sorted at sorting plants [25]. 


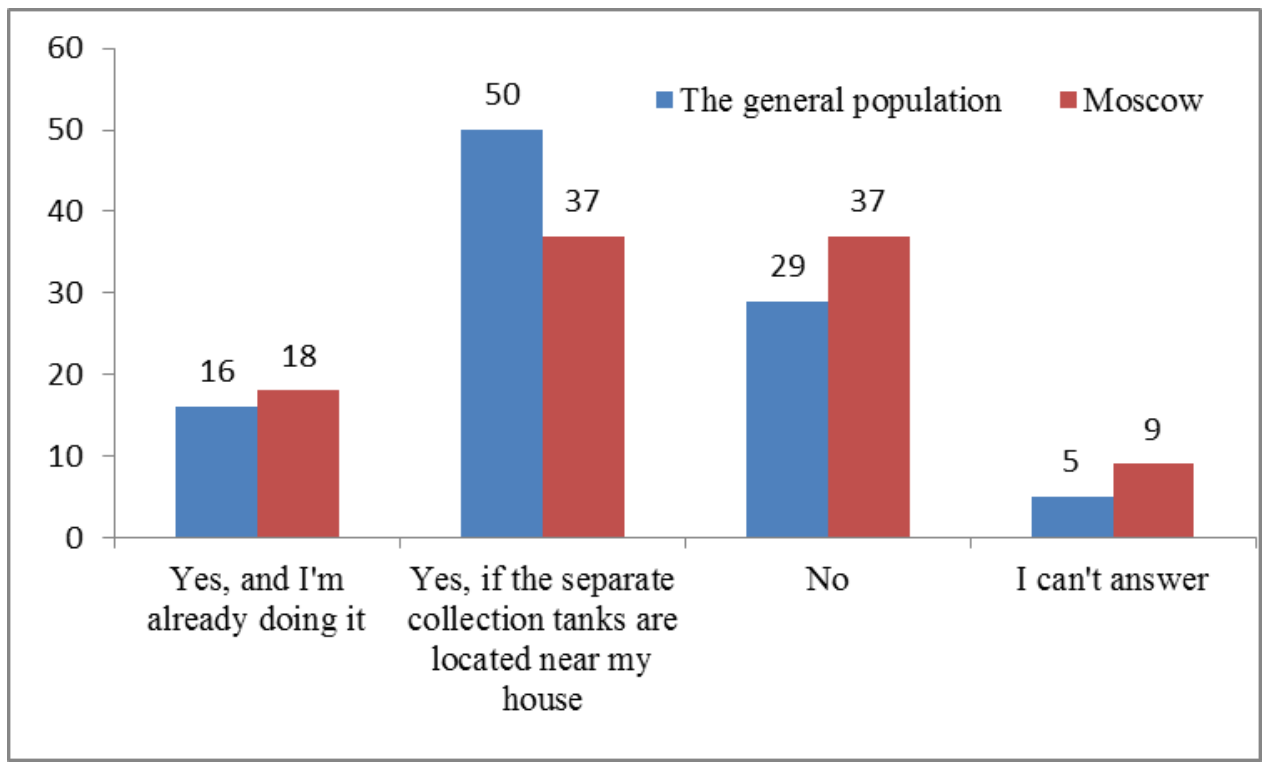

Fig. 3. Are you ready to sort garbage at home for further recycling? (Levada Analytical Center, 2019) [25].

\subsection{Information campaign on segregation of waste collection}

In response to the request "separate waste collection" from January 1 to September 20, 2020 in the database Public.ru found 119 publications in regional media. So it can be said that the Moscow authorities conducted an information campaign in the regional press.

In the city a lot of work was done to equip sites for separate waste collection, so by January 1, 22 thousand sites with 60 thousand containers were equipped. And the information campaign according to the city authorities in the first half of the year led to an increase in the volume of waste collected for recycling in Moscow by $60 \%$. About this "News" on August 11, 2020 reported to the Deputy Mayor of Moscow in the city government of Petr Birukov.

The Moscow press reports that in Moscow the acceptance of works for the contest of the best posters "Help the city - sort waste", campaigning for separate collection of municipal waste, has ended, the press service of the housing and utilities Department reported. But there is no information about how these posters are used for further information work in the city.

You can also find out from Moscow Newspapers that Moscow schools pay a lot of attention to environmental education. There are environmental events, quizzes, kids doing research. In schools the action "Good caps" is held. This is a social and environmental project for the charity collection of plastic caps to help children with special needs. The collected caps are sent for processing, and the proceeds go to buy wheelchairs and other special devices necessary for children with special developmental needs. There are special containers in the halls on the first floor for the reception of the caps.

A few months ago, the Department of ZHKH of Moscow launched the project "Moscow shares". This is a department account in "Instagram" where citizens share their experience of separate waste collection. They publish environmental videos with the participation of celebrities who tell why a responsible approach to waste disposal is so important [26]. 
In the North of the capital, most of the comments from citizens are caused by the very location of garbage containers on the site and the incorrect placement of gray and blue containers inside them. This is the responsibility of the HIC department. In particular, the tanks are often stuffed into the garbage cans and are not visible. The wipers are not properly positioning the containers inside the sites. Residents also say that the recyclable nets were more convenient, as it was seen lying there.

People interviewed by the newspaper "Nash Sever"(Our North) confirmed that the information campaign on the separate collection was not powerful enough. "Ecoline" shows an impressive list of activities to promote waste sorting as an excuse and promises to continue the campaign. The government of Moscow has its own television channel, newspaper «Evening Moscow» and district and municipal newspapers, information on this topic of separate waste collection should appear there all the time.

In the press there is also a mobile application for questions on waste disposal, which was launched by "Ecoline" company. The main function of this application is the requests of the residents for garbage removal. But there is also a section "Other" where you can find out where to put special waste (thermometers, batteries).

Based on the analysis of the Moscow media, it can be concluded that the work on informing the population in the press is carried out. And there's an education program in schools. A poster competition was held, but there was no indication of how the posters were used in the city.

\subsection{Analysis of programs on the channel Moscow 24}

In 2020 the channel Moscow 24 released 16 programs devoted to the topic of separate waste collection [27]. We should straight away note the limits that were adopted during the process of analysis. The information about the amount of news posts was not used during the analysis as there is no access to it. Several programs were analyzed.

In a TV spot called «Investigation: we wasted 40000 rubles in order to find out where the trash goes» TV reporter Boris Laurer carried out an investigation in Moscow about where the trash is taken out by transport companies. Following companies were tested "Ecoline", "Spetztrans", "Charter", "MSC-NT", "MKM-logistic". The conclusion was made that almost all the companies except for "Spetztrans" take the recyclable materials out to the marshalling yards. This TV spot informs the viewers that their labour in sorting waste is not in vain. The video collected 252000 views on YouTube.

TV spot "Bottle caps that save children's lives" which is about "Kind caps" action, organized by the "Volunteers helping orphans" fund tells about this project's work. The action works in a following way: people take bottle caps to collection points, when the number of caps is big enough, it gets weighed and sent to the Tver Plastic processing plant. The plant buys bottle caps for 25 rubles per kilogram, it is material that will be recycled. The plant transfers the money on charity fund's account. The money is spent on orphans' needs. This project is extremely important, because it solves two topical problems of society - garbage sorting and helping children in orphanages.

In the program "A Day on a Garbage Truck" the TV journalist showed the work of a garbage truck of the MKM-Logistics company. The waste truck travels from 80 to 200 points during one shift, at each point there is 1 tank with recyclable materials. And the journalist drew attention to the fact that the population is not sorting waste yet and for that reason food products end up in containers with recyclable materials. From that fact we can conclude that the practice of sorting garbage has not yet taken hold.

The video "Collector" tells about the unique ecological project "Collector" and its leader Lera Korasteleva. Collector was launched in 2018. The project accepts 100 types of raw materials. But only 20 types of raw materials can be exchanged for money, the remaining 
80 types are not accepted. At the same time, only 8 types of raw materials can be sent to recyclable containers. The video tells about eco-activists who come to the "Collector" and sort trash as volunteers. However, this is only a small part of the population; most have not yet entered the practice of sorting garbage.

In the process of analyzing 4programs, we found out that the population has not yet joined the practice of sorting garbage, and so far, we can talk about the fragmentation of the practice of sorting garbage by the population. At the same time, bins for separate trash collection are installed and trash collection services are efficient. The programs "Sortirovochnaya" gain from 10 to 20 thousand views on the YouTube channel. But the program "Investigation: we wasted 40000 rubles in order to find out where the trash goes" received 252 thousand views. Which speaks of the great interest of the population in the question of where the recyclable materials are exported.

\section{Discussion}

Having discussed the result of the analysis carried out by the author, we can conclude that the introduction of separate waste collection and its development is one of the most important environmental tasks in our country. In Moscow, the first steps have been taken so far in the systematic development of infrastructure for separate waste collection and raising awareness among the population. And it is important to note that the start of an information campaign on separate waste collection coincided with an information campaign on the fight against coronavirus. And it is also important to keep in mind that the process of overlapping these companies will continue in the future, which reduces their effect. A huge amount of work has been done to develop waste collection platforms near dwellings, and containers are installed at all existing container sites. But there are many issues that need to be addressed. And these issues can be resolved if further sociological research is carried out to improve the quality of environmental education. In the study, it is important to understand how not only to inform Moscow residents about separate waste collection, but also to increase their confidence in the new infrastructure. Analysis of foreign experience has shown directions for further research.

The most important issue is how to raise awareness of the population and the further development of skills for sorting garbage. In essence, we are talking about the formation of new behaviour among Moscow residents based on ecological attitudes and behavioural practices. The analysis showed that a lot has already been done, namely: an information campaign has been launched on the Moscow 24 channel and in the Moscow press, environment friendly lessons are being held in schools, and sorting workshops at "Collector" (Sobirator) are held. However, there is a need for further information work to increase interest in separate waste collection. To use the existing media and continue to involve the Moscow 24 channel, since it is their programs that help educate the population. At school, the formation of environmental values in children is achieved by regular classes on proper waste management. But since the school curriculum does not include the discipline "Ecology", it is possible to conduct environmental lessons within the framework of several school disciplines, so that children could constantly develop their environmental awareness.

In the process of analyzing Moscow newspapers, we found out that there was a competition for the best posters "Help the city - sort the rubbish". It is very important to use these posters for further propaganda, especially in areas with waste containers. In addition, it is very important to upload videos with instructions on waste sorting in Moscow transport. Andit's important in these videos and posters, not only to raise the environmental awareness of citizens, but also to provide detailed instructions on sorting waste at home. 
Pay attention to issues related to recyclable waste, to the need of washing plastic and glassware for sorting, how to organize storage space at home.

Educational films really work, as we have seen from the experience of Europe, where waste sorting has become a daily practice of citizens. However, an analysis of foreign media says that not only education, but also training of citizens was carried out. And besides this, it is important to create infrastructure and transparent rules for sorting waste. And then we can gradually introduce a reduction in tariffs for the removal of sorted waste. Because people have different values and citizens with high environmental awareness (about 18\%) are already involved in this process. We should also consider an economic factors. It is very important to start using economic incentives such as tariff reductions.

Another direction of work is to attract senior household chores and TSN members to this work. Tell us about the rules of sorting in transport, as well as how to organize work in chats.

Another important factor is increasing public confidence in the created infrastructure. And in this case, important work is being carried out by the Moscow 24 channel about garbage disposal, sorting garbage at sorting plants, and further processing of garbage. In addition, the opportunity to visit the sorting plants held by "Ecoline". It is necessary to investigate what other factors can increase the confidence of citizens.

\section{Conclusion}

Currently, a huge amount of work has been done: containers have been installed near houses, in yards. A big information campaign is being carried out on the channel "Moscow 24 ", which increases confidence in the waste management process in the city that the sorted waste will be recycled. In Moscow, other projects are also being carried out ("Kind Caps", "Collector"), which contribute to the development of the skills of separate waste collection among the population. A lot of educational work is being done with schoolchildren to develop ecological mindset. And it is also necessary to develop education on social media and to begin working with neighboring communities. But so far, the bulk of the population has not joined the waste sorting process, this fact requires constant actions from the authorities.

\section{References}

1. A. Oke, J. Kruijsen, Recycling, 1, 271-285 (2016)

2. A. Ebreo, J. Vining, Environmental Management, 25, 153-168 (2000)

3. P. Luyben, S. Cummings, Journal of Environmental System, 111, 235-245 (1981)

4. S. McDonald, C. Oates, Conservation and Recycling, 39, 369-385 (2003)

5. B. Jeroen, J.C.J.M, Ecological Economics, 66, 559-574 (2008)

6. J. Vining, A. Ebreo, Environmental Behaviour, 22, 55-73 (1990)

7. M. Pothitou, R.F. Hanna, K.J. Chalvatzis, Appl Energy, 184, 1217-1229 (2016)

8. T. Evison, A.D. Read, Conservation and Recycling, 32, 275-292 (2001)

9. S. Vasdev, G.B. Jean Paulo, WorldBankblog (2016) https://blogs.worldbank.org/taxonomy/term/15794

10. D. Hoornweg, B.P. Bhada-Tata, Urban Development Series. World Bank, 15 (2012)

11. S. Miafodzyeva, N. Brandt, Waste and Biomass Valorization, 4(2), 221-235 (2013) 
12. A. Bruvoll, B. Halvorsen, K. Nyborg, Resources, Conservation and Recycling, 36(4), 337-354 (2002)

13. B. Halvorsen, Land Economics, 84(3), 501-516 (2008)

14. R. Afroz, K. Hanaki, R. Tuddin, K.A. Ayup, Waste Management and Research, 28(2), 552-560 (2010)

15. C. Berglund, Ecological Economics, 56(4), 560- 569 (2006)

16. E.S. Iyer, R.K. Kashyap, Journal of Consumer Behaviour, 6(1), 32-47 (2007)

17. K. Refsgaard, K. Magnussen, Journal of Environmental Management, 90(2), 760771(2008)

18. A. Kirakozian, Applied Economics, 48(16), 1481-1503 (2016)

19. F. Bogner, The Journal of Environmental Education, 29, 11-16 (1998)

20. W. Abrahamse, Energy Conservation through Behavioral Change: Examining the Eff Ectiveness of a Tailor-Made Approach (University of Groningen, Groningen, Netherlands, 2007)

21. M.A. Shabanova, Social Sciences., 50(2), 3-20 (2019)

22. Order of the Department of housing and utilities of Moscow No. 01-01-14-590\19 dated December 26, 2019 "On approval of the territorial scheme of waste management of the city of Moscow (2019) https://www.mos.ru/dgkh/documents/view/232950220/

23. Resolution of the government of Moscow No. 734-PP of June 18, 2019 "On the implementation of measures for the separate collection (accumulation) of solid municipal waste in the city of Moscow" (2019)

24. Weekly poll "Omnibus", held on 22-23 Feb 2020 (2020) https://fom.ru/posts/14357

25. Garbage reform and separate waste collection: results of the March survey (2019) https://www.levada.ru/2019/05/15/musornaya-reforma

26. The housing and utilities Department launched a project on separate garbage collection in social networks https://news.rambler.ru/ecology/44883942-departament-zhkhzapustil-v-sotssetyah-proekt-o-razdelnom-sbore-musora/

27. Moscow 24 Sortirovochnaya Channel 